\title{
REPRESENTAÇÕES SOCIAIS DO TRÂNSITO PARA MOTORISTAS
}

Washington Allysson Dantas Silva

Universidade Federal da Paraíba
Recebido em: 11/04/2020

$1^{\text {a }}$ revisão em: 02/11/2020

$2^{\text {a }}$ revisão em: 16/02/2021

Aceito em: 12/05/2021

\section{RESUMO}

Este estudo analisou as representações sociais do trânsito para motoristas brasileiros. Participaram 110 pessoas, com idades entre 19 e 62 anos $(M=27,9$; $D P$ $=9,44$ ), de diferentes regiões do Brasil. Os sujeitos responderam a um questionário sociodemográfico e um teste de associação livre de palavras (TALP) com os estímulos indutores "motociclistas", "pedestres" e "engarrafamento". Os resultados demonstraram que os motoristas, em sua maior parte, representam o trânsito brasileiro de modo pessimista e negativo. A palavra "estresse" foi a mais utilizada para representar o "engarrafamento". Os dados são discutidos à luz da psicologia social e do trânsito.

Palavras-chave: psicologia do trânsito; estresse; representação social. 


\section{SOCIAL REPRESENTATION OF TRAFFIC FOR DRIVERS}

\section{ABSTRACT}

This study aimed to investigate the social representation of traffic for Brazilian drivers. The sample was 110 people, aged between 19 and 62 years old ( $M=27.9$, $S D=9.44$ ), living in different regions from Brazil. A word association test (WAT) was performed with three stimulus inductors, "motorcyclists", "pedestrians" and "traffic jam". The results showed that drivers, for the most part, represent Brazilian traffic in a pessimistic and negative way. In this sense, the word "stress" was used as more frequent to stimulus "traffic jam". The findings are discussed in the light of social and traffic psychology.

Keywords: traffic psychology; stress; social representation.

\section{REPRESENTACIONES SOCIALES SOBRE TRÁNSITO PARA LOS CONDUCTORES}

\section{RESUMEN}

Este estudio tuvo como objetivo investigar las representaciones sociales del tráfico brasileño para los motoristas. Participaron en el estudio un total de 110 personas, de 19 a 62 años $(M=27.9$; SD = 9.44), de diferentes regiones de Brasil. Los participantes respondieron un cuestionario sociodemográfico y una prueba de asociación de palabras (PAP) con los estímulos inductores "motocicleta", "peatón" y "embotellamiento". Los resultados mostraron que los conductores, en su mayor parte, representan el tráfico brasileño de una manera pesimista y negativa. Por ejemplo, la palabra "estrés" se usó como más frecuente para el estímulo "embotellamiento". Los hallazgos se discuten a la luz de la psicología social y del tráfico.

Palabras clave: psicología del tránsito; estrés; representación social. 


\section{INTRODUÇÃO}

Diante da mudança ideológica sobre o uso do automóvel no Brasil, pautado não somente como meio de locomoção, mas também de manutenção do status social, objeto de desejo e privilégio (Pitanga, 2012), se faz importante a discussão sobre como motoristas orientam as suas ações a partir do conhecimento e dos afetos que possuem frente ao trânsito, como também das situações e dos atores que o circundam (e.g., engarrafamento, motociclistas e os próprios motoristas), questionando-os sobre qual a representação social que possuem acerca desse espaço social. É essa a problemática em que o presente estudo se insere.

Sabe-se que trânsito pode ser definido de diferentes formas. Rozestraten (1986), por exemplo, discutia que o trânsito poderia ser compreendido como um problema social, no qual os atores sociais e seus veículos disputam espaço e posições, de acordo com seus interesses. Desse modo, na visão do autor, o trânsito seria um eterno conflito na sociedade. Conceitualmente falando, o Código de Trânsito Brasileiro (CTB) institui que trânsito é "a utilização das vias por pessoas, automóveis e animais, isolados ou em grupos, conduzidos ou não, para fins de circulação, parada, estacionamento e operação de carga ou descarga" (Brasil, 1997, p. 1). Ainda neste documento, é expressado que o trânsito é "um direito de todos e dever dos órgãos e entidades componentes do Sistema Nacional de Trânsito, a estes cabendo, no âmbito das respectivas competências, adotar as medidas destinadas a assegurar esse direito" (Brasil, 1997, p. 1).

Dessa maneira, o CTB é claro e incisivo ao compreender o trânsito como um meio social intrínseco à vida urbana. Assim, como consequência dessa urbanidade, são estabelecidas determinadas regras sociais para o perfeito funcionamento do trânsito (e.g., sinalização e código de conduta), uma vez que se trata de um convênio na sociedade. À guisa de definição, considera-se como motoristas, neste estudo, todo cidadão que detém a Carteira Nacional de Habilitação $(\mathrm{CNH})$ sob as concessões de nível B (concessão para dirigir carros), A e B (concessão para carros e motos) ou $D$ (concessão para dirigir veículos de transportes urbanos, seja ônibus, vans, etc.). Denomina-se os que possuem habilitação para pilotar motocicletas ( $\mathrm{CNH}$ de nível A) de motociclistas, sendo estes componentes de um grupo social com diferentes demandas e desafios no trânsito do que os motoristas (Jesus et al., 2017).

Em relação à Psicologia, existe uma disciplina específica que discute a relação entre os processos psicossociais e o trânsito, denominada de Psicologia do Trânsito (PT). Cabe sinalizar que o desenvolvimento dessa disciplina teórica e prática encontrase atrelada ao desenvolvimento da legislação do trânsito no Brasil. No trabalho de Cardoso et al. (2011) são discutidas as fases do desenvolvimento da PT no Brasil, indo desde as primeiras avaliações psicológicas conduzidas com candidatos à Carteira Nacional de Habilitação até o momento atual, no qual, a partir da criação do CTB, vem se aumentando a conscientização popular sobre o papel do psicólogo 
do trânsito e de sua importância na criação de políticas públicas específicas para esse contexto.

Um fato marcante na história da PT no Brasil foi a promulgação da Resolução do Conselho Federal de Psicologia 14/2000 (revogada posteriormente pela Resolução CFP 13/2007), que estabelecia os critérios normativos para a obtenção do título de Psicólogo Especialista do Trânsito, sendo este uma exigência para os profissionais que trabalhavam ou visavam atuar neste campo. Dentre as atribuições dessa especialidade, encontram-se: proceder ao estudo no campo dos processos psicológicos, psicossociais e psicofísicos relacionados aos problemas de trânsito; analisar os acidentes de trânsito, considerando os diferentes fatores envolvidos para sugerir formas de evitar e/ou atenuar as suas incidências; realizar avaliação psicológica em condutores e candidatos à $\mathrm{CNH}$ (Conselho Federal de Psicologia, 2018).

Sobre esse último ponto, a Resolução CFP 01/2019 institui as normas e procedimentos para a realização de perícias psicológicas no âmbito do trânsito (Conselho Federal de Psicologia, 2019a). Essa resolução revoga as já existentes CFP 007/2009 e 009/2011 e foi resultado de um amplo debate no Conselho Nacional de Trânsito entre psicólogos, Departamentos Estaduais de Trânsito (Detrans) e pesquisadores da área. Dentre as novidades trazidas pela resolução destacam-se o estabelecimento do termo "perícia psicológica" para designar a avaliação psicológica realizada pelo psicólogo do trânsito e o documento gerado no final desse processo, o atestado psicológico, como estabelece a Resolução CFP 06/2019 (Conselho Federal de Psicologia, 2019b).

Desse modo, a PT pode ser conceituada como uma "área que estuda, através de métodos científicos válidos, os comportamentos humanos no trânsito e os fatores e processos externos e internos, conscientes e inconscientes que os provocam ou os alteram" (Rozestraten, 1988, p. 9). Ancorada nesta definição, Hoffman (2005) afirma que a psicologia do trânsito pode ser compreendida como "o estudo do comportamento do usuário das vias e dos fenômenos/processos psicossociais subjacentes ao comportamento" (p. 17). Esta autora aborda que, além das ações preconizadas por resoluções específicas para o psicólogo do trânsito, este profissional também pode atuar frente a algumas temáticas de pesquisa, como: atitudes, percepção de risco, estilo de vida, procura de emoções e representações sociais. É sobre essas representações sociais que o presente trabalho pretende se debruçar.

\section{REPRESENTAÇÕES SOCIAIS (RS) E A TEORIA DO NÚCLEO CENTRAL (TNC)}

Como explanado anteriormente, uma das possibilidades de atuação em Psicologia do Trânsito compreende a investigação das representações sociais dos participantes sobre o trânsito e seus correlatos (e.g., políticas públicas relacionadas ao trânsito, como a lei seca). De forma interdisciplinar, este campo da psicologia dialoga com a Psicologia Ambiental, a Psicologia Educacional, a Psicologia dos 
Desastres e a Psicologia Social em busca de respostas às problemáticas encontradas nesse meio (e.g., acidentes, emoções, comportamentos de risco), sendo a Psicologia Social o terreno fértil das representações sociais.

O conceito de representações sociais proposto por Serge Moscovici $(2012,2013)$ e delimitado sob a concepção de núcleo central-estruturante (Abric, 2003), é colocado como ponto norteador na construção da presente pesquisa. De acordo com Moscovici (2012), as RS são teorias do senso comum que guiam as ações de um grupo na sociedade. Essas representações são formadas num sistema de significados coletivos sobre o meio social e atuam diretamente na formação de sentimentos e afetos dos indivíduos, orientando o conhecimento e as atitudes dos membros de diferentes grupos sociais.

Os sistemas de representações emergem, portanto, da interação entre os indivíduos e os grupos sociais, sendo mediada pela cultura e pela linguagem, a qual possibilita o contato e a interpretação da realidade desconhecida pelos sujeitos (Moscovici, 2013). Assim, pode-se representar uma pessoa ou um objeto, por exemplo, criando-se símbolos que facilitam a comunicação, através dos quais as representações sociais serão formadas e, por sua vez, guiarão as ações sociais. Por sua função-guia, as RS podem contribuir na formação de atitudes sociais, assim como crenças e estereótipos intergrupais.

Nessa mesma direção, encontra-se a perspectiva teórica da abordagem estrutural de Abric (2003), a qual busca conhecer a estrutura de uma representação social, em uma hierarquia imagética e cognitiva formada por um núcleo central e elementos periféricos (Sá, 1996). De acordo com esse autor, o núcleo central pode ser compreendido como o elemento mais estável de uma representação, o qual delimita seus significados, sua consistência e permanência, resistindo a mudanças de significações ao longo da história. Logo, o núcleo central pode ser compreendido como uma estrutura objetiva e principal de uma representação social. Por sua vez, os elementos periféricos representam, na teoria, estruturas mais instáveis e passíveis de mudança com o decorrer do tempo. São formados a partir do núcleo central, dando flexibilidade para a estrutura principal, possibilitando mudanças contextuais no conteúdo dessas representações (Abric, 2003).

Desse modo, pesquisas sobre representações sociais utilizam instrumentos de coleta de dados como escalas Likert (Assis \& Matthes, 2014), entrevistas com roteiros estruturados, semiestruturados ou abertos (Marinho et al., 2019), e a técnica de associação livre de palavras (Vergès, 1992; Yamauchi et al., 2019). Consequentemente, para pesquisar as representações sociais do trânsito brasileiro para condutores de automóveis defende-se neste trabalho a possibilidade de buscar a estrutura em que essas representações são formadas (i.e., o núcleo central e os elementos periféricos), e como elas se apresentam na visão de 110 pessoas da população geral brasileira. Esse grupo de participantes é formado exclusivamente por motoristas sobre o qual será analisada a forma como produzem o conhecimento sobre a realidade do trânsito e como reproduzem as suas opiniões 
e atitudes nesse espaço social. Especificamente, buscou-se observar como esses motoristas representam os componentes motociclistas, engarrafamento e motoristas, com vista a identificar os núcleos centrais e os elementos periféricos de cada uma dessas categorias de análise.

\section{MÉTODO}

Esta é uma pesquisa de abordagem quanti-qualitativa, de caráter exploratório e descritivo, delineada a partir do referencial teórico das representações sociais em sua abordagem estrutural.

\section{PARTICIPANTES}

Participaram deste estudo 110 pessoas, residentes em diferentes regiões do Brasil, sendo 58 mulheres e 52 homens, de faixa etária entre 19 e 62 anos ( $M=27,9$; DP $=9,44)$, residentes na região Nordeste, Sudeste, Sul e Centro-Oeste, com renda familiar acima de 5 salários mínimos (34,5\%), de estado civil solteiro $(67,3 \%)$, com nível superior incompleto (50,0\%), sem filhos $(75,5 \%)$, sendo $40,2 \%$ estudantes.

\section{INSTRUMENTOS}

Foram utilizados como instrumentos de coleta de dados o Questionário Sociodemográfico e o Teste de Associação Livre de Palavras (TALP). Estes instrumentos foram dispostos online, na plataforma Google Forms e compartilhados nas redes sociais. A aplicação do TALP consistiu em solicitar aos participantes que escrevessem até três palavras que rapidamente emergissem em sua mente, após a leitura de cada um dos estímulos indutores, em ordem, "motociclista", "engarrafamento" e "motoristas". Não foi solicitado que atribuíssem uma ordem de importância às palavras, nem uma explicação do porquê associaram os estímulos com tais evocações.

\section{PROCEDIMENTOS}

A pesquisa seguiu os aspectos éticos explanados na Resolução 466/2012 do Conselho Nacional de Saúde, que preconiza os parâmetros para a realização de pesquisas com participação de seres humanos no Brasil. O projeto foi submetido à Plataforma Brasil para apreciação ética, sendo o estudo iniciado após a aprovação do Comitê de Ética da Universidade Federal da Paraíba sob o parecer n. 3.788.890.

Aos/as participantes, foi solicitada a assinatura do Termo de Consentimento Livre e Esclarecido (TCLE), no qual eram dispostas informações que remetiam à seguridade do sigilo de informações e do anonimato, esclarecendo questões quanto a voluntariedade na participação, a desobrigação do fornecimento das informações solicitadas, além da possibilidade de desistência a qualquer momento, sem nenhuma penalização. A assinatura do TCLE, a idade mínima de 18 anos e a posse da Carteira Nacional de Habilitação tipo B (concessão para dirigir 
automóveis), A e B (concessão para automóveis e motocicletas) foram critérios adotados para a inclusão dos sujeitos no estudo ou $\mathrm{D}$ (concessão para transporte de veículos de transporte humano, como por exemplo ônibus).

\section{ANÁLISE DE DADOS}

Os dados sociodemográficos foram processados pelo Statistical Package for the Social Sciences for Windows (IBM SPPS), versão 24.0, e os decorrentes do TALP pelo IRAMUTEQ (Interface de R pour les Analyses Multidimensionnelles de Textes et de Questionnaires), versão 0.7 - alpha2. Para estudar as representações sociais de cada um dos componentes de análise sobre o trânsito (e.g., motociclista, engarrafamento e motoristas), foi utilizada a Análise Fatorial de Correspondência (AFC). Além disso, para confirmar a estrutura das representações, priorizou-se a técnica da Análise de Similitude, a qual se baseia na teoria dos grafos e possibilita a organização gráfica dos elementos centrais e periféricos das representações a partir da criação de árvores máximas com as evocações mais relacionadas entre si.

Para o tratamento das representações sociais, os termos evocados foram digitados e organizados com o auxílio do programa Bloco de Notas (Windows), constituindo o corpus de análise, sendo distribuídos entre as três classes específicas a que se referiam (e.g., motociclistas, pedestres e engarrafamento). Optou-se por este programa pela similaridade da extensão de saída do arquivo com a da leitura do corpus textual realizada pelo programa IRAMUTEQ. De cada classe, foram selecionados os termos com frequência igual ou maior que cinco (5) para a construção de histogramas e gráficos de barras. Essa estratégia de análise foi escolhida, em oposição à análise prototípica, por esta oferecer uma representação gráfica do fenômeno estudado.

\section{RESULTADOS}

As evocações para cada estímulo indutor foram representadas de três formas: frequência de termos, AFC, e Análise de Similitude (Vala, 2013). A figura 1 apresenta a frequência de termos para o estímulo "motociclista".

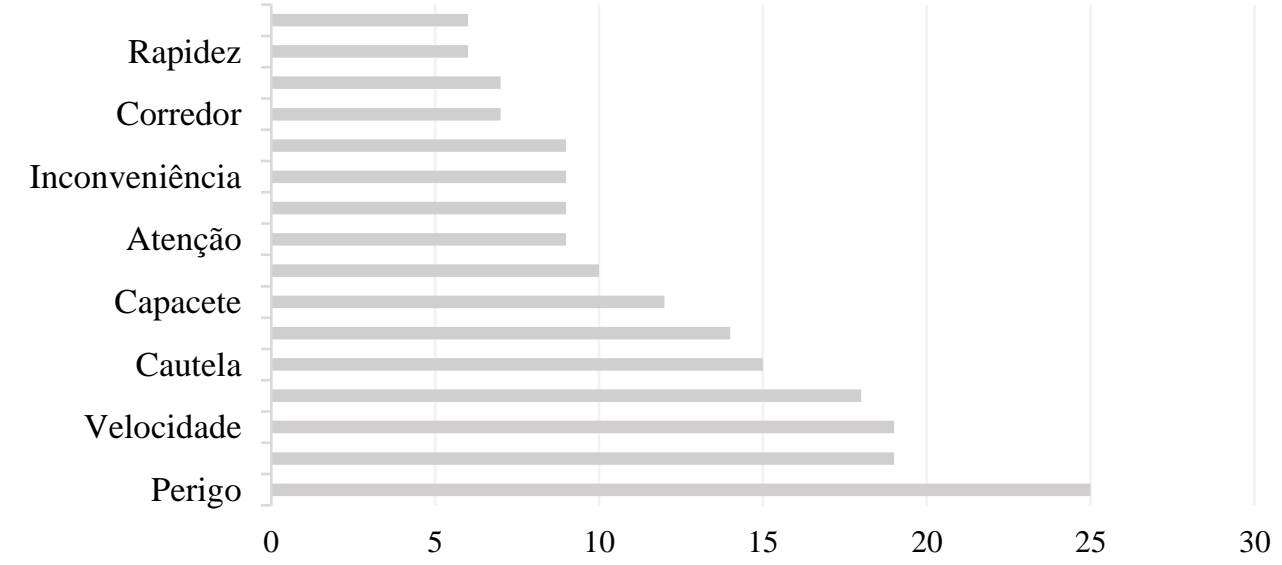

Figura 1. Palavras evocadas na TALP do "motociclista" (14,94\% das ocorrências). 
Como observado na Figura 1, foram evocadas 308 palavras ao estímulo "Motociclistas". Ocorreram 86 palavras diferentes e 46 hápax (i.e., palavras com frequência igual a um). Observou-se que o termo perigo foi o mais frequente, seguido de velocidade e cautela

Ao realizar a AFC, o IRAMUTEQ permitiu a visualização das oposições resultantes entre as evocações relacionadas a esse estímulo. Como mostrado na Figura 2, foi observada a existência de quatro classes em quadrantes opostos, cada uma abrangendo contextos semânticos específicos.

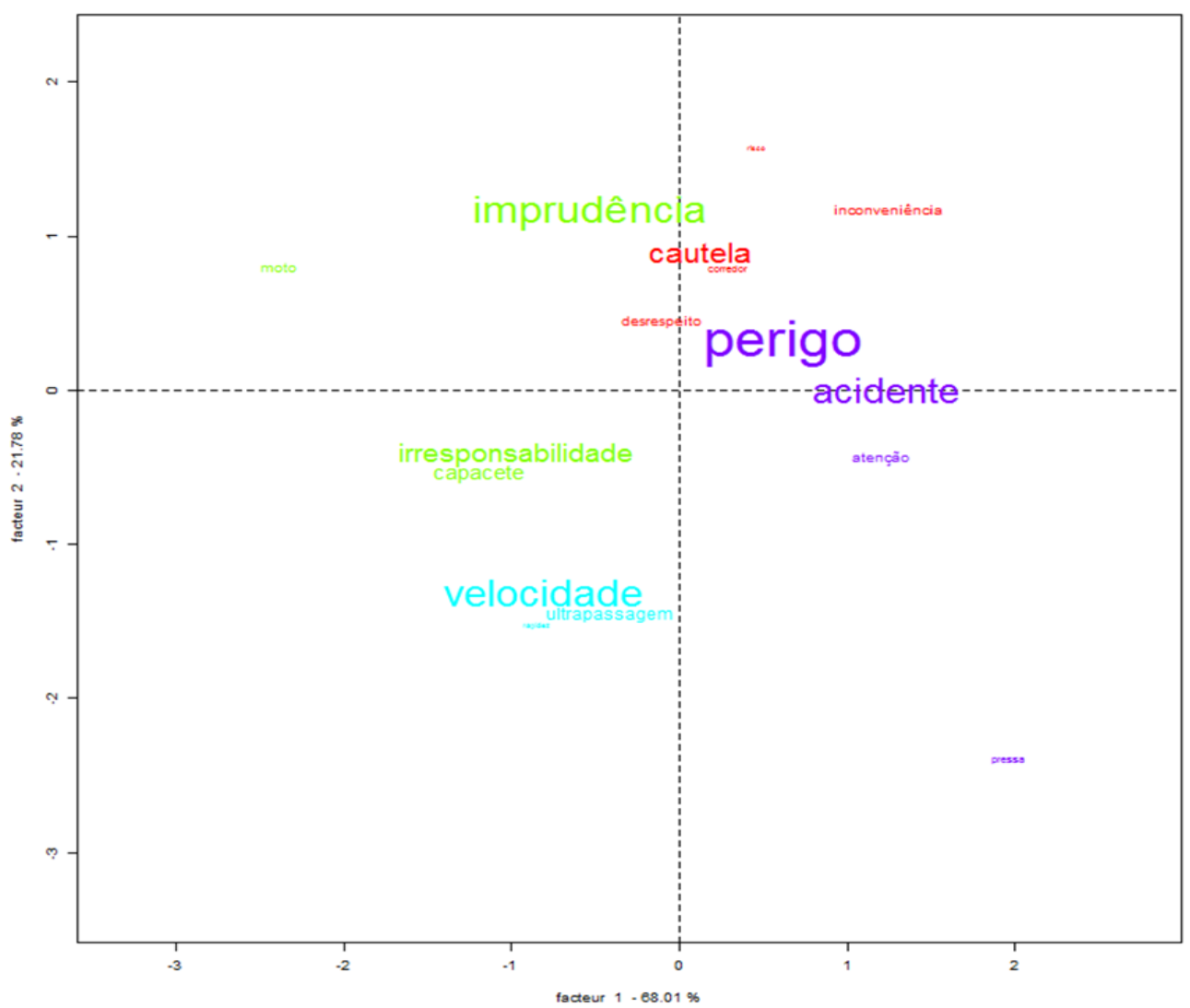

Figura 2. Análise Fatorial de Correspondência (AFC) sobre o termo "motociclista".

A exemplo do quadrante 1 (quadro superior esquerdo), pode-se observar a semelhança parcial entre os termos moto e imprudência. Em oposição, no quadrante 4, visualiza-se as palavras atenção, acidente e pressa, sendo esta última a mais distante nestas correspondências. Esse resultado demonstra como os motoristas observam os motociclistas nas vias públicas, sendo uma imagem negativa formada pela falta de atenção e imprudência como possibilidade de causa de acidentes. O quadrante 2 e 3 opõem-se entre si, sinalizando como núcleo central o vocábulo perigo, tanto em termos situacionais (a exemplo das palavras capacete, corredor e risco), como da conduta deste sujeito (irresponsabilidade, velocidade, rapidez e ultrapassagem, assim como desrespeito e inconveniência). 
Estes termos foram divididos em quatro classes, sendo as palavras centrais de cada uma delas, respectivamente: classe 1, perigo; classe 2, imprudência; classe 3, irresponsabilidade; e classe 4, velocidade. Esses resultados permitem visualizar que o termo central de toda a análise, isto é, a representação social dos participantes em relação aos motociclistas urbanos brasileiros, é o "perigo" que, como mencionado, pode estar relacionado com fatores situacionais/estruturais/ambientais e individuais/subjetivos tanto do sujeito que respondeu, como do sujeito a que a se refere as respostas. Para confirmar a centralidade dos elementos desta categoria, realizou-se a análise de similitude (Figura 3). Essa técnica favorece a visualização das conexões entre os termos que circundam as representações acerca de determinado objeto, expressando a força dessa relação em um plano gráfico.

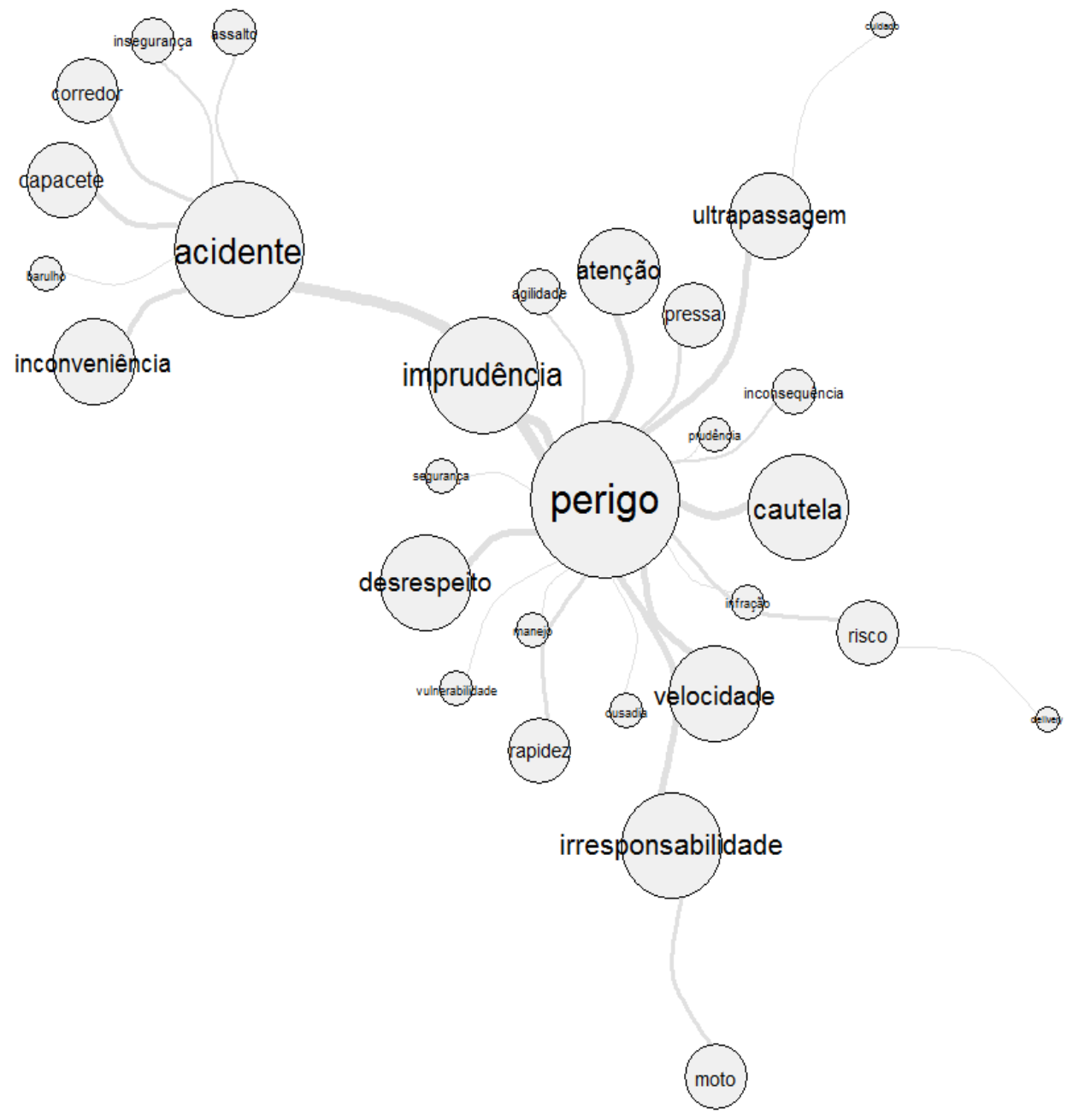

Figura 3. Análise de Similitude sobre o termo "motociclista".

A partir da Figura 3, se confirma o termo "perigo" como o núcleo central da representação social dos participantes acerca dos motociclistas no trânsito brasileiro. Através da leitura dos termos que circundam esta representação, é possível observar que os participantes percebem os motociclistas como sujeitos 
imprudentes, desatentos, ousados e irresponsáveis, cuja pressa, velocidade e inconsequência podem gerar riscos e infrações, colocando-os em situações de vulnerabilidade.

Destaca-se como uma das classes semânticas desta representação a evocação do termo acidente, o qual remete a situações de uso ou não de capacete, à manobra de ultrapassagem pelo "corredor" e à insegurança relacionada aos assaltos realizados com uso de motocicletas, colocando este sujeito como um indivíduo que também pode oferecer riscos. Ainda, corroborando com esta representação negativa dos motociclistas, encontra-se o termo cuidado na extremidade do campo lexical, cuja distância e baixa magnitude da relação com os demais termos possibilita a compreensão de que esse é um termo que se distancia da representação social dos motociclistas. Dito de outra forma, para motoristas, não consta em sua representação o cuidado dos motociclistas em relação ao trânsito.

Passando para o próximo termo indutor, o estímulo "engarrafamento", observa-se a ocorrência de 320 termos, sendo 100 formas distintas e 57 hápax (Figura 4).

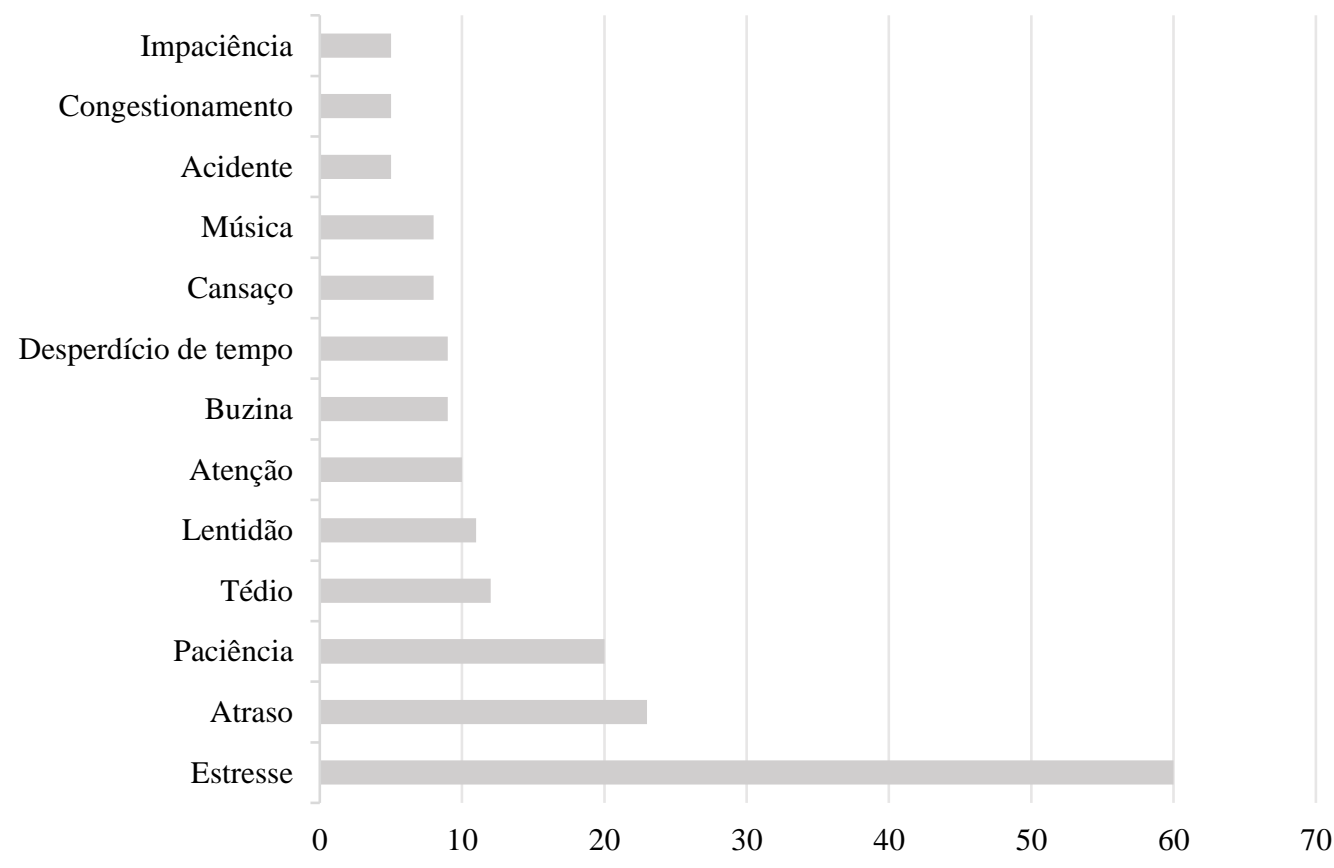

Figura 4. TALP "engarrafamento" (17,81\% das ocorrências).

A partir das frequências de evocações ao estímulo engarrafamento, observa-se o termo estresse como o mais comum nas respostas dos participantes. Porém, esse dado por si só não permite afirmar que esse termo se trata do núcleo central de sua representação social. Para esse fim, prosseguiu-se com a AFC (Figura 5), com objetivo de investigar quantas e quais classes compõem a representação social desta categoria. 


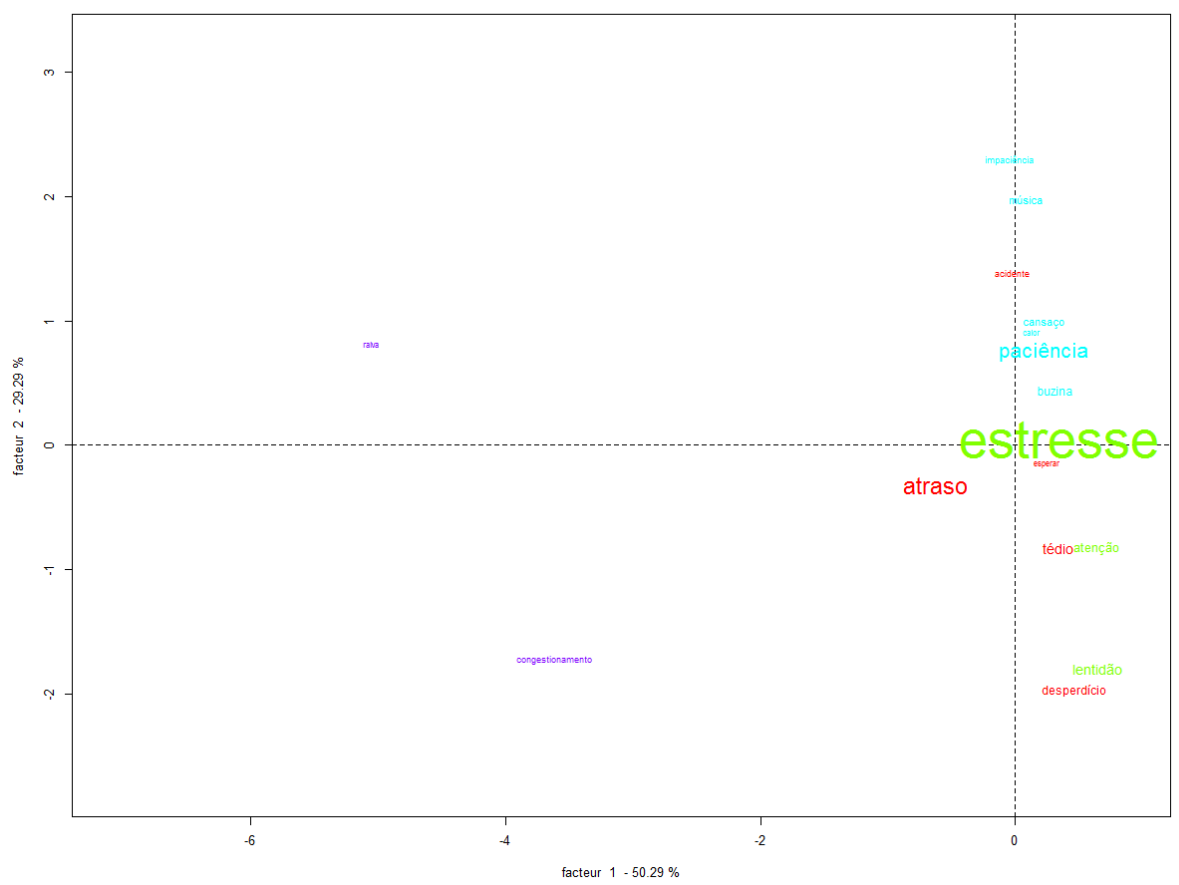

Figura 5. AFC das evocações sobre o termo "engarrafamento".

Os resultados da AFC confirmaram a concepção do estresse como núcleo central da representação social do engarrafamento. Além disso, foram observadas quatro classes semânticas, sendo os eixos principais de cada uma, respectivamente, estresse, atraso, paciência e congestionamento. Além da AFC, procedeu-se à análise de similitude (Figura 6), com vistas a confirmar os resultados encontrados através de uma estrutura gráfica para melhor visualização.

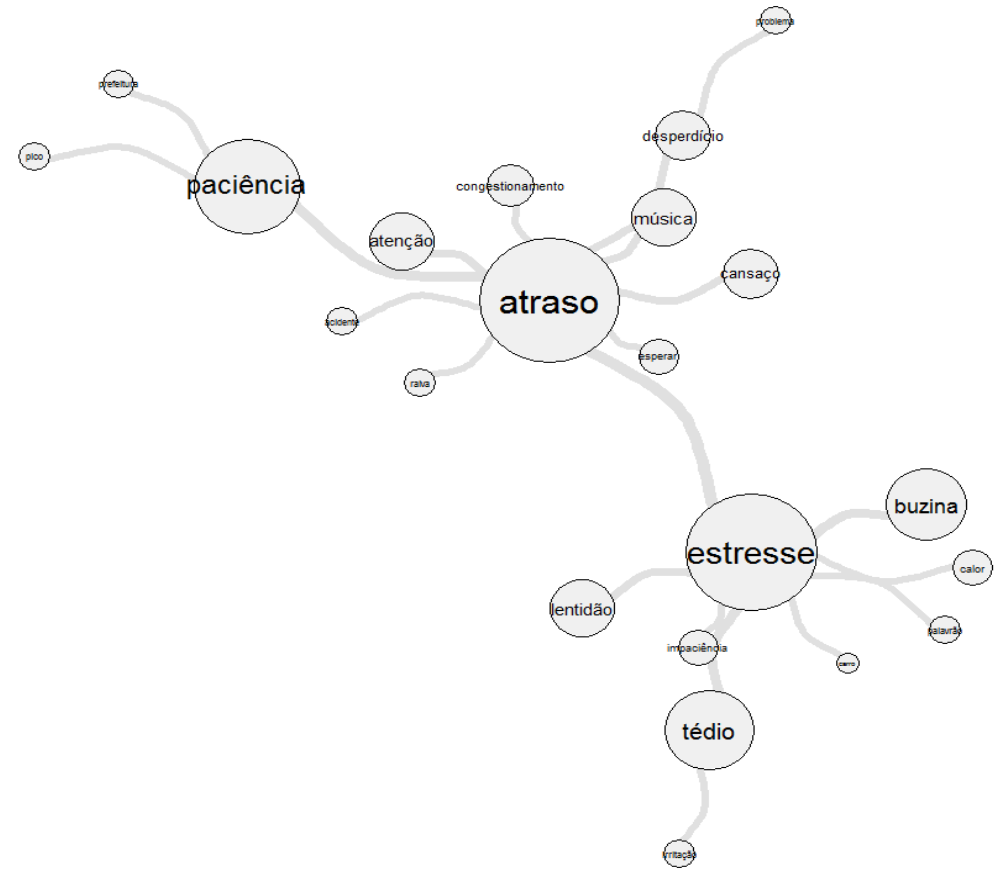

Figura 6. Análise de Similitude sobre o termo "engarrafamento". 
A análise de similitude confirma os resultados decorrentes da AFC demonstrando que o estresse foi apontado como relevante e entendido como o núcleo central da representação social dos motoristas sobre o engarrafamento. Entretanto, a partir da leitura dos elementos periféricos, percebe-se que essa representação está relacionada ao atraso gerado por esta situação no trânsito, dada a forte relação entre os termos. Palavras como desperdício, tempo, raiva, música, congestionamento e acidente explicam os significados atribuídos a essa representação social. Ainda, o termo estresse se relacionou com as evocações buzina, lentidão, calor, impaciência e tédio. Todos esses termos configuram ? a realidade do trânsito brasileiro em horários em que há um número elevado de veículos nas vias terrestres, o qual implica na formação de engarrafamentos.

A expressão indutora seguinte, "Motoristas", apresentou 322 ocorrências de evocações, sendo 112 formas e 66 hápax. A partir de ocorrências iguais ou superiores a cinco, observou-se os termos responsabilidade (28), atenção (25), cuidado (24), carro (16) e respeito (13) como mais frequentes.

Como na análise dos estímulos anteriores, para verificar o núcleo central e os elementos periféricos da representação social, realizou-se tanto a AFC quanto a análise de similitude. A AFC (Figura 7) demonstrou que, para a maioria dos participantes, a representação social do motorista é vinculada a termos como responsabilidade (classe 1), cuidado (classe 2), carro (classe 3) e trânsito (classe 4). As classes foram decompostas em dois pontos opostos (quadrantes 1 e 3 ), situados próximos à extremidade: segurança e acidente.

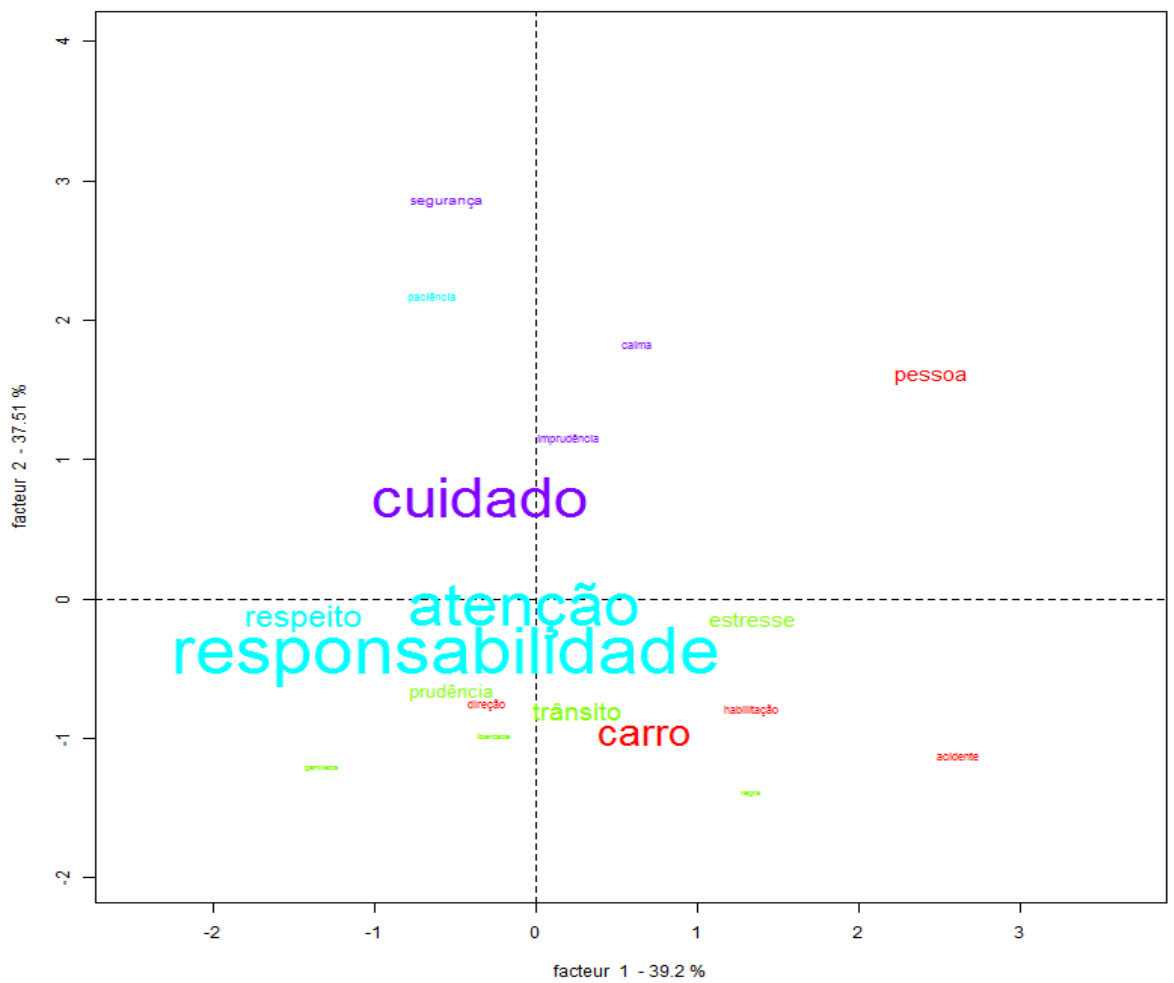

Figura 7. AFC sobre o termo "motorista". 
O resultado da análise de similitude (Figura 8) evidenciou o termo cuidado como o núcleo central da representação dos motoristas sobre si mesmos. Trata-se, portanto, da defesa pelo cuidado no trânsito, retratado pelos termos que circundam o elemento central, especificamente regra, segurança, prudência, calma.

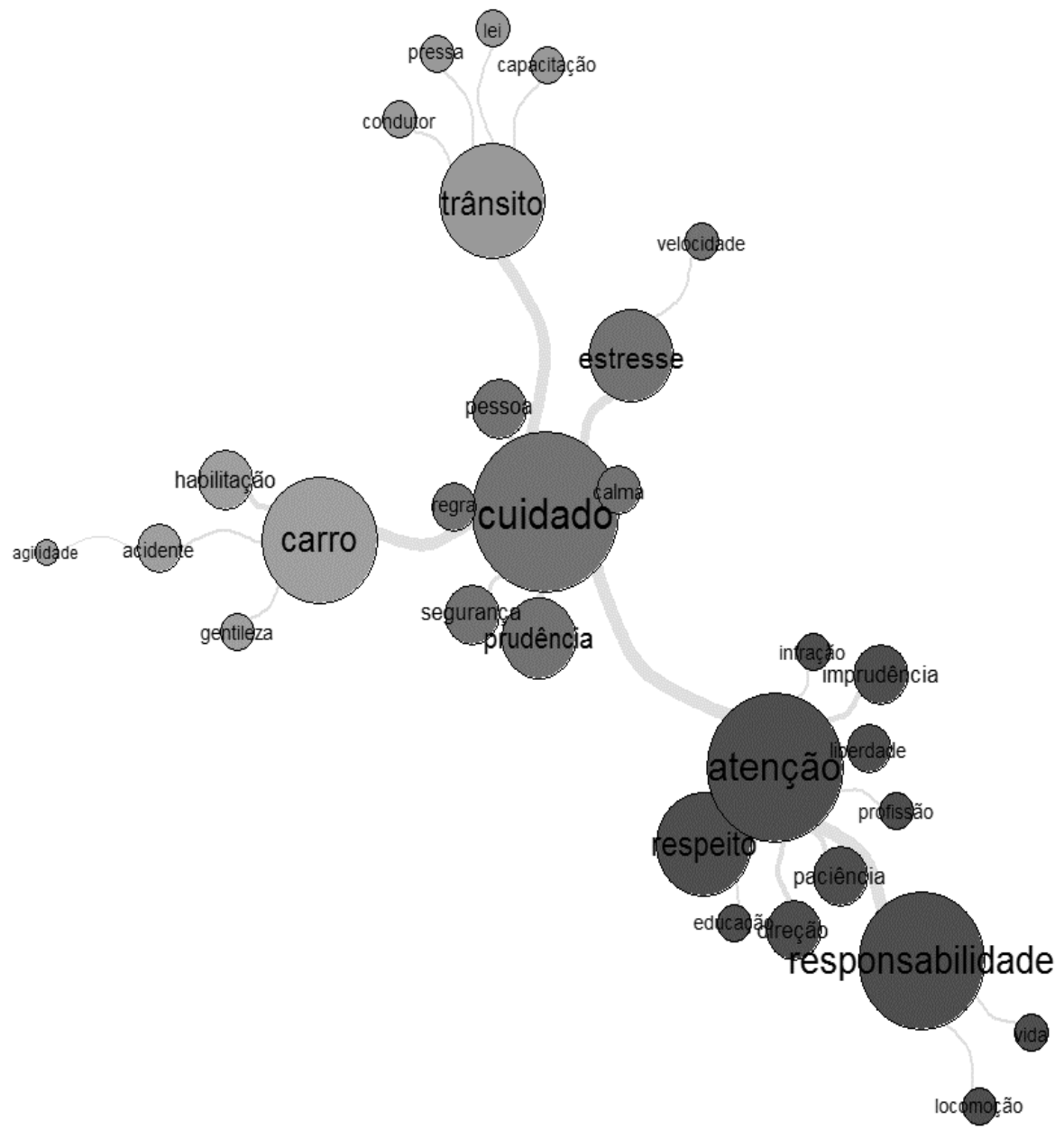

Figura 8. Análise de Similitude sobre o termo "motorista".

Com base na Figura, observa-se que as ramificações do núcleo central cuidado foram atenção e responsabilidade (interligadas entre si), ancorados no cuidado com a infração, imprudência, liberdade, paciência e educação. O carro, enquanto instrumento, foi significado como uma ferramenta que possibilita agilidade na vida cotidiana.

\section{DISCUSSÃO}

A leitura das representações sociais permite a compreensão acerca de como os sujeitos dão sentido à realidade, além de como organizam suas atitudes e ações sociais. Neste estudo foram observadas diferentes representações acerca do trânsito brasileiro na visão de 110 motoristas da população geral. Para o grupo 
estudado, os motociclistas são representados negativamente, como sendo uma ameaça para o trânsito, dada a sua imprudência e falta de cautela. O engarrafamento foi discutido como um fator de estresse e de atraso, enquanto que a categoria "motoristas" foi representada por termos como cuidado, responsabilidade e atenção.

A representação social negativa atribuída ao motociclista pode ser explicada pela sujeição desse grupo a determinados comportamentos de risco no trânsito brasileiro. No seu estudo de revisão, Jesus et al. (2017) identificaram que uma das principais causas de acidentes no trânsito é a imprudência dos motociclistas quanto ao uso desse espaço público. As autoras discutem que diferentes fatores podem predispor essa problemática, a exemplo do aumento da frota de motocicletas e o uso cada vez mais expressivo da motocicleta como ferramenta de trabalho e lazer, além das características individuais dos motociclistas. Estando esses veículos em maior circulação nas vias terrestres, somada à falta de educação preventiva para o trânsito por parte dos motociclistas, maior é a vulnerabilidade a acidentes vivenciada por esses condutores.

Nesse mesmo sentido, entre 2009 e 2018, os acidentes de trânsito acarretaram um custo de quase três bilhões de reais ao Sistema Único de Saúde (Conselho Federal de Medicina, 2019). Em 2017, especificamente, houve 181,2 mil internações decorrentes desse tipo de acidente, sendo mais de $50 \%$ envolvendo motociclistas, gerando um gasto de R $\$ 259$ milhões ao Estado. Ainda, segundo o Ministério da Saúde (Brasil, 2017), a motocicleta é notificada como o meio de locomoção mais utilizado pelas vítimas $(62,2 \%)$ de acidentes terrestres no Brasil. Logo, argumentase que essa representação vai muito além de uma competição entre motoristas e motociclistas (Moreira et al., 2018), mas elencam as informações acerca do impacto gerado pelos acidentes com motociclistas para a saúde e segurança pública, gerando a imagem do motociclista enquanto um perigo, enquanto núcleo central dessa representação social.

Sobre a representação social do engarrafamento, os resultados parecem demonstrar que o sentido atribuído ao estresse e ao atraso remete ao conflito social estabelecido neste espaço, como discutido por Rozestraten (1986). Dado o interesse individual e não coletivista, observa-se cada vez mais o acúmulo de automóveis e motocicletas em disputa pelas vias terrestres, denotando a pouca adesão às políticas de incentivo ao uso de transportes públicos, transformando o trânsito em um espaço de tensão e desigualdade social no Brasil (Pitanga, 2012).

Quanto à representação social do motorista, foi observado um processo de favorecimento endogrupal (Tajfel \& Turner, 1979). Logicamente, motoristas também atuam de modo irresponsável nas vias terrestres, envolvendo-se em acidentes no trânsito, que geram custos para os cofres públicos. Porém, a mera categorização social (e.g., motociclistas e motoristas) permitiu que os motoristas representassem o seu grupo de forma positiva, enquanto os do exogrupo (e.g., motociclistas) de maneira negativa, desfavorecendo-os em suas representações, 
evidenciando, assim, sua identidade social. Esse resultado se assemelha aos do estudo de Miranda e Nascimento (2018), no qual os motoboys de Belo Horizonte utilizaram processos identitários para representarem a si mesmos em relação à sua masculinidade. Nessa direção, sugere-se que em estudos futuros sejam verificadas as representações sociais de motociclistas acerca dos motoristas no trânsito, com vistas à replicação dos resultados deste estudo, mas agora tomando outro grupo como referência.

Em linhas gerais, o presente trabalho colabora com a Teoria das Representações Sociais (Moscovici, 2012, 2013) por apresentar uma investigação inovadora sobre uma variável psicossocial pouco abordada dentre aquelas comumente encontradas nos trabalhos que utilizam essa perspectiva teórica. Ao pautar o trânsito enquanto elemento condutor da pesquisa, foi verificado que as representações sociais auxiliam na formação de atitudes e comportamentos de condutores frente aos estímulos estudados, reforçando o postulado das representações sociais enquanto guias das ações humanas.

Futuramente, espera-se que novos estudos venham ser realizados dentro dessa linha de pesquisa de modo que, a partir do método utilizado e amparado pela investigação prévia das representações sociais, seja possível a predição de comportamentos e atitudes no trânsito, sendo essa uma das limitações deste estudo. Além disso, o número de participantes foi muito reduzido, não possível realizar generalizações quanto aos resultados. Sugere-se que em estudos futuros seja priorizada uma amostra mais representativa da população, sendo levadas em considerações, também, questões como a influência do gênero na utilização de vias terrestres, uma vez que se vem observando que a maior parte dos envolvidos em acidentes de trânsito no Brasil são pessoas do gênero masculino (BarrosoJunior et al., 2019), sendo este um problema de pesquisa pertinente para a Psicologia Social. Por fim, logra-se que este trabalho possa fomentar novos debates sobre o papel do psicólogo nesse meio social, uma vez que o Conselho Federal de Psicologia é categórico e objetivo quanto às diretrizes que guiam o exercício profissional do profissional especialista no trânsito.

\section{REFERÊNCIAS}

Abric, J. C. (2003). Abordagem estrutural das representações sociais: desenvolvimentos recentes. In P. H. F. Campos \& M. C. S. Loureiro (Orgs.), Representações sociais e práticas educativas (pp. 37-57). Goiânia: UCG.

Assis, C. L., \& Matthes, G. A. S. (2014). Representações sociais sobre a psicologia e o psicólogo em universitários de uma faculdade privada de Rondônia, Brasil. Aletheia, (43-44), 66-90. Recuperado de http://pepsic.bvsalud.org/scielo.php?script=sci_arttext\&pid=S1413 03942014000100006\&lng=pt\&tlng=pt

Barroso-Junior, G. T., Bertho, A. C. S., \& Veiga, A. de C. (2019). A letalidade dos acidentes de trânsito nas rodovias federais brasileiras. Revista Brasileira de Estudos de População, 36, 1-22. https://doi.org/10.20947/S0102-3098a0074

Brasil. (1997). Lei nº. 9.503, de 23 de setembro de 1997: Código de Trânsito Brasileiro. Brasília: Diário Oficial da União. 
Brasil. (2017). Viva Inquérito 2017: Vigilância de Violências e Acidentes em Serviços Sentinelas de Urgência e Emergência. Brasília: Ministério da Saúde.

Cardoso, H. F., Santos, M. M., \& Santos, T. M. M. (2011). Psicologia do trânsito: Análise sistemática da literatura na SciELO, Redalyc e PePSIC. Revista Ensaios: Extensões, 5(1), 35-45. https://doi.org/10.22409/re.v1i5.526

Conselho Federal de Medicina. (2019). Medicina de tráfego: transporte seguro de crianças em veículos automotores. Brasília: Conselho Federal de Medicina.

Conselho Federal de Psicologia. (2018). Referências técnicas para atuação de psicólogas(os) em políticas públicas de mobilidade humana e trânsito. Brasília: Conselho Federal de Psicologia.

Conselho Federal de Psicologia. (2019a). Resolução No 1, de 07 de fevereiro de 2019. Brasília: Conselho Federal de Psicologia.

Conselho Federal de Psicologia. (2019b). Resolução N 6, de 29 de março de 2019. Brasília: Conselho Federal de Psicologia.

Hoffmann, M. H. (2005). Comportamento do condutor e fenômenos psicológicos. Psicologia: Pesquisa \& Trabalho, 1(1), 17-24. Recuperado de http://pepsic.bvsalud.org/pdf/ppet/v1n1/v1n1a04.pdf

Jesus, V. F., Rocha, F. C., Ferreira, A. S. S., Alves, A. P. O., \& Siqueira, L. G. (2017). Causas associadas aos acidentes de trânsito envolvendo motociclistas: revisão integrativa. Revista de Enfermagem do Centro-Oeste Mineiro, 7(1), 1-8. https://doi.org/10.19175/recom.v7i0.1514

Marinho, F. D., Nardi, S. T., Avellar, L. Z., \& Coutinho, G. C. (2019). Temor e insignificância: representações sociais da hanseníase para adolescentes com a doença. Psicologia, Saúde \& Doenças, 20(1), 192-208. https://dx.doi.org/10.15309/19psd200116

Miranda, G. R., \& Nascimento, A. R. A. (2018). Masculinidades em trânsito: processos identitários de motoboys em Belo Horizonte - MG. Temas em Psicologia, 26(2), 637-651. https://dx.doi.org/10.9788/TP2018.2-05Pt

Moreira, M. R., Ribeiro, J. M., Motta, C. M., \& Motta, J. I. J. (2018). Mortalidade por acidentes de transporte de trânsito em adolescentes e jovens, Brasil, 1996-2015: cumpriremos o ODS 3.6? Ciência \& Saúde Coletiva, 23(9), 2785-2796. https://dx.doi.org;10.1590/141381232018239.17082018

Moscovici, S. (2012). A psicanálise, sua imagem e seu público. Petrópolis: Vozes.

Moscovici, S. (2013). Representações sociais: investigação em psicologia social. Petrópolis: Vozes.

Pitanga, C. V. (2012). Fé em Deus e pé na tábua: ou como e por que o trânsito enlouquece no Brasil. Horizontes Antropológicos, 18(37), 399-402. https://dx.doi.org/10.1590/S010471832012000100021

Rozestraten, R. J. A. (1986). A Psicologia Social e o trânsito. Psicologia: Ciência e Profissão, 6(2), 22-23. https://dx.doi.org/10.1590/S1414-98931986000200007

Rozestraten, R. J. A. (1988). Psicologia do trânsito: Conceitos e processos básicos. São Paulo: E.P.U.

Sá, C. P. (1996). Núcleo central das representações sociais. São Paulo: Vozes.

Tajfel, H., \& Turner, J. C. (1979). An integrative theory of intergroup conflict. In W. G. Austin \& S. Worchel (Eds.), The social psychology of intergroup relations (pp. 33-47). Monterey: Brooks/Cole.

Vala, J. (2013). A análise de conteúdo. In A. S. Silva \& J. M. Pinto (Orgs.), Metodologia das ciências sociais (pp. 101-130). Porto: Afrontamento.

Vergès, P. (1992). L'évocation de l'argent: une méthode pour la définition du noyau central de la représentation. Bulletin de Psychologie, 45, 203-209.

Yamauchi, L. M., Andrade, A. L. M., Pinheiro, B. O., Enumo, S. R. F., \& Micheli, D. (2019). Social representation regarding the use of alcoholic beverages by adolescents. Estudos de Psicologia (Campinas), 36, e180098. https://doi.org/10.1590/1982-0275201936e180098

\section{CONFLITOS DE INTERESSES}

Não há conflitos de interesses. 


\section{SOBRE O AUTOR}

Washington Allysson Dantas Silva é psicólogo (CRP 13/10028), mestre e doutorando no Programa de Pós-Graduação em Psicologia Social (PPGPS) da Universidade Federal da Paraíba (UFPB).

E-mail: allysson dantas@hotmail.com

(3) https://orcid.org/0000-0002-0556-8936 